\title{
A EDUCAÇÃO EM DIREITOS HUMANOS DIANTE DA ASCENSÃO DO “NOVO FASCISMO"
}

HUMAN RIGHTS EDUCATION BEFORE THE ASCENSION OF "NEW FASCISM"

Thais Aparecida Dibbern', Evandro Coggo Cristofoletti ${ }^{2}$

RECEBIDO EM: 11/09/2017 / APROVADO EM: 20/10/2017

DOI: $10.5902 / 2317175829004$

\section{RESUMO}

Este artigo busca discutir as potencialidades e limites da Educação em Direitos Humanos (EDH) diante das "novas" ondas conservadoras e fascistas que permeiam a democracia moderna. Metodologicamente, o trabalho foi desenvolvido através de uma revisão bibliográfica da literatura científica sobre a temática dos direitos humanos fundamentais e da "nova onda fascista", bem como da análise de documentos oficiais do Governo Federal que tratam especificamente sobre a EDH, buscando compreender como o ensino superior, mais precisamente a universidade pública, se insere dentro dessa temática. Visualiza-se que a EDH se constitui enquanto alternativa local para o enfrentamento do "novo fascismo" através da promoção e defesa de valores referentes aos direitos humanos com vistas à uma transformação ético-cultural; porém, limita-se por não considerar as contradições presentes na própria democracia liberal no quadro do modo de produção capitalista que, a depender do contexto, cria as bases para o fortalecimento de grupos e movimentos conservadores e "neofascistas".

Palavras-chave: Direitos humanos; Fascismo; Universidade; Compromisso social.

1 Mestranda do Programa de Pós-graduação Interdisciplinar em Ciências Humanas e Sociais Aplicadas pela Faculdade de Ciências Aplicadas da Universidade Estadual de Campinas (Unicamp). E-mail: dibbern.thais@gmail.com 2 Doutorando em Política Científica e Tecnológica pelo Departamento de Política Científica e Tecnológica da Universidade Estadual de Campinas (Unicamp). E-mail: evandro.coggo@gmail.com 
A EDUCACÃO EM DIREITOS HUMANOS DIANTE

DA ASCENSÃO DO "NOVO FASCISMO"

\begin{abstract}
This article aims to discuss the potentialities and limits of Human Rights Education (EDH) in the face of the "new" conservative and fascist waves that permeate modern democracy. Methodologically, the work was developed through a bibliographical review of the scientific literature on the theme of fundamental human rights and the "fascist new wave", as well as the analysis of official Federal Government documents that deal specifically with HRE, seeking to understand how the higher education, more precisely the public university, is part of this theme. It is seen that the EDH constitutes as a local alternative to the confrontation of the "new fascism" through the promotion and defense of values referring to human rights with a view to an ethical-cultural transformation; but it is limited by not considering the contradictions present in liberal democracy itself within the framework of the capitalist mode of production which, depending on the context, creates the basis for the strengthening of conservative and neo-fascist groups and movements.
\end{abstract}

Keywords: Human rights; Fascism; University; Social Commitment.

\title{
1 Introdução
}

O fascismo do século $X X$ constituiu-se como um sistema político antidemocrático, ultranacionalista e autoritário que visava o culto da tradição, a supremacia do militarismo guiado pela vigilância extrema por parte do Estado, bem como a exacerbação do sexismo e o desprezo pelos direitos humanos. Há quem diga que essa doutrina política e social não mais exista, uma vez que pressupõe uma mobilização de massas, estando incompatível com o regime democrático. Porém, considera-se, neste artigo, que o fascismo adquiriu novas configurações, manifestando-se de forma difusa e não declarada diante da realidade econômico, política e sociocultural contemporâneas. Nesse sentido, muitas vezes, coloca-se em xeque o debate acerca dos direitos humanos fundamentais, havendo grandes movimentos ligados à direita e à extrema-direita que acabam por confirmar o fortalecimento do pensamento conservador e, no limite, a ascensão desse "novo fascismo".

Na contramão desse processo, a Educação em Direitos Humanos (EDH) apresenta-se como uma prática educativa capaz de fomentar uma maior reflexãoacerca dos direitos humanosfundamentais historicamenteconstituídos, bem como uma transformação cultural com vistas ao empoderamento e emancipação de atores sociais. Dessa forma, argumenta-se que a EDH, quando efetivamente integrada e inserida em todos os níveis de ensino, inclusive no âmbito da universidade pública - produtora de conhecimento, de formação e de extensão -, pode vir a ser uma das alternativas concretas, em âmbito local, ao combate dos problemas relatados anteriormente.

Em visto disso, o objetivo deste artigo consiste em discutir, em âmbito teórico, alguns limites e potencialidades da Educação em Direitos Humanos à 
luz das ondas conservadoras e fascistas que permeiam a democracia moderna. Busca-se na literatura as respostas para as seguintes perguntas: como a EDH poderia contribuir ao combate desse "novo fascismo"? Como ela poderia ser organizada ou materializada para tal? E, quais seus limites?

Metodologicamente, a pesquisa, de caráter exploratório, foi realizada com base em revisões bibliográficas acerca da temática proposta, bem como um levantamento de documentos oficiais do Governo Federal que visam legitimar essa prática educativa no âmbito nacional. Logo, organizase da seguinte forma: a primeira parte do artigo é dedicada a explorar o debate sobre as ondas conservadoras e fascistas que permeiam a democracia moderna a fim de caracterizá-las; objetiva-se também, nessa parte, explorar algumas contradições desses fenômenos que, no seio das democracias liberais modernas, fortalecem-se diante das reconfigurações do capitalismo global. Em seguida, apresentaremos a Educação em Direitos Humanos (EDH) enquanto um direito fundamental integrado ao direito à educação, configurando-se como uma das formas de superação do cenário a ser apresentado na etapa anterior. Faz-se necessário destacar que esta parte em específico buscará dialogar com os documentos oficiais do Governo Federal, de forma a fundamentar a incorporação da EDH no ambiente escolar e acadêmico, concretizando e exemplificando o debate realizado em âmbito teórico. Por fim, apresentamos as considerações finais deste artigo, pontuando as descobertas quanto às potencialidades e limites da EDH no que se refere aos problemas aqui debatidos e à luz das teorias apresentadas.

Anteriormente ao desenvolvimento da argumentação, faz-se necessário tecer algumas ressalvas metodológicas. Em primeiro lugar, o caráter exploratório do artigo funda-se na compreensão de que o "novo fascismo" é um fenômeno complexo, em constante movimento e transformação, que possui muitas vezes um caráter velado e fragmentado que dificulta a captura de suas causas e consequências. Dito isso, optou-se por utilizar, em grande medida, referências que buscassem as raízes desses fenômenos nos processos de mudança estrutural pelo qual o capitalismo passou a partir da década de 1970; bom ressaltar que, apesar disso, considerou-se outras perspectivas para compor o debate. Tomouse, nesse sentido, que tal problemática decorreria, em alguma medida, da própria dinâmica econômica global. Desse modo, a EDH configura-se como alternativa concreta local e limitada justamente por se enquadrar no âmbito da própria democracia liberal burguesa. Em outras palavras, o estudo buscou explorar as causas do "novo fascismo" nas dinâmicas econômicas, geopolíticas e culturais engendradas pelas transformações ocorridas no capitalismo pós 1970 para, depois, explorar as potencialidades da EDH, enquanto possibilidade concreta e imediata, no combate a esses novos fenômenos autoritários e na defesa dos direitos humanos fundamentais. Por fim, uma última ressalva: não abordaremos, neste artigo, o chamado fascismo clássico'.

1 A caracterização do fascismo clássico, relativos ao período entre guerras mundiais, pode ser encontrado de forma mais detalhada em Bobbio (2007) e Paxton (2007). 


\section{A ascensão do "novo fascismo" e suas configurações}

A concepção contemporânea dos direitos humanos perpassou por um intenso processo histórico de universalização que contribuiu para a formação do sistema internacional e nacionais de direitos humanos, sobretudo após o reconhecimento das atrocidades cometidas durante a Segunda Guerra Mundial. Tais direitos trazem consigo a ideia geral de proteção da dignidade da pessoa humana, isto é, pressupondo o reconhecimento de que todos somos sujeitos de direitos, sem distinções relacionadas à religião, raça, classes sociais, etc. Nesta perspectiva, tal debate encontra-se intrinsecamente relacionado ao de democracia, uma vez que a garantia de liberdades fundamentais conjectura na condição de dar voz às pessoas acerca de questões de caráter público, com fins a assegurar o controle popular sobre as decisões governamentais (BEETHAN, 1998).

No entanto, faz-se necessário destacar que tal relação é complexa, visto que mesmo em regimes democráticos podem haver violações de direitos e restrições às liberdades fundamentais, bem como negação de direitos, assim como nos apresenta Dallari (2010): ainda que haja direitos assegurados na Constituição, a realidade nos mostra que grande parte dos brasileiros não gozam desses "privilégios", sendo evidente a distorção de preceitos legais de dispositivos da C.F./88. Ademais, por vivermos em sociedades multiculturais, nas quais diferentes perspectivas se contrapõem e se defrontam, ideias contrárias à perspectiva de direitos humanos e até mesmo de democracia liberal podem vir à tona, não estando intrínsecas apenas à regimes autoritários e/ou ditatoriais. Desse modo, estando compatíveis com a democracia, perspectivas conservadoras e fascistas acabam por minar tais princípios, abrindo espaço para questionamentos.

John Gray (2000), filósofo liberal, concebe que a "tolerância liberal" se deriva das divisões imputadas às sociedades monoculturais, pressupondo um consenso em matéria de valores, a qual coloca limites à diversidade de crenças e práticas, constituindo-se apenas como um projeto de moderação e respeito. Seu herdeiro natural/sucessor, no entanto, não é a neutralidade, mas sim o projeto de modus vivendi humano, o qual se decorre no entremeio de diferentes modelos de vida. Desse modo, reconhece-se que nas sociedades modernas muitas pessoas interagem entre diferentes tradições, havendo resistências morais perante tal multiculturalismo. Esse pluralismo valórico, contudo, acaba por colocar em xeque o próprio ideal da "tolerância liberal". Esse ideal não se constituiu como um processo de reconhecimento de legitimidade e justificação de outros modos de vida, mas sim como um projeto de moderação e respeito a outras crenças e práticas; ele expressava uma forma comum de vida pautada em princípios éticos, conjecturando-se em sociedades múltiplas e multiculturais. Isso, em uma perspectiva liberal, possibilitaria um pluralismo valórico - "um consenso cultural em matéria de valores" (GRAY, 2000, p. 78) - importante às sociedades democráticas. Todavia, segundo esse autor, esse ideal tornou-se quimérico, uma vez que diante da existência de tal pluralismo, 
torna-se impossível um consenso que pressuponha a coexistência pacífica entre diferentes sociedades, havendo um processo de profunda diversidade, desarmonização e intolerância no âmbito das sociedades multiculturais.

Dessa forma, as manifestações neofascistas e ultraconservadoras são vistas como "distorções" éticas e valorosas em relação aos ideais da democracia liberal e multicultural. Em outras palavras, ao nosso ver, são explicadas por uma espécie de "resquício" de ideologias totalitárias que afloram em determinados contextos políticos, culturais, econômicos e sociais.

Porém, em outra perspectiva, a qual abordaremos com mais profundidade a partir de agora, trata-se de reconhecer que o fascismo se manifesta em regimes democráticos por razões intrínsecas ao próprio sistema democrático liberal burguês; ou melhor, pode originar-se no seio de suas contradições, a depender de configurações históricas econômicas e políticas próprias do modo de produção capitalista em nível local e global. Nesse sentido, não se pode esquecer que a democracia liberal - e os próprios direitos humanos - desenvolvem-se sob o marco do modo de produção capitalista e estão sujeitos às contradições inerentes a esse sistema (TONET, 2002; 2005). É nessa perspectiva que os autores abaixo irão conceber o novo fascismo: são fenômenos enraizados nas contradições do ideal burguês de democracia (e de liberdade, justiça, respeito e tolerância) e não podem ser dissociados dos determinantes da infra-estrutura econômica. Desse modo:

Teríamos, então, três posições a respeito da problemática dos Direitos Humanos. A primeira, do marxismo tradicional, para a qual estes direitos, por serem direitos de caráter burguês, deveriam ser suprimidos por qualquer revolução socialista. A segunda, que também propugna uma sociedade socialista, mas que entende que aqueles direitos (e o conjunto dos direitos e institutos democrático-cidadãos), por terem um caráter universal, não só não devem ser suprimidos, como devem ter sua validade implementada nesta nova sociedade. A terceira, a posição liberal-democrática, que defende o aperfeiçoamento desta ordem social, e para a qual a luta pela proteção, ampliação e melhoria dos Direitos Humanos estaria inserida nesta luta maior pelo aperfeiçoamento de uma sociedade cada vez mais democrática. A posição liberal, ao meu ver, é equivocada e por vários motivos. Em primeiro lugar porque pressupõe que esta forma de sociabilidade, capitalista, é a última, sendo utópica uma forma superior pretensamente socialista. Em segundo lugar, porque pressupõe como fato indiscutível que são o direito e a política que fundam a sociedade e que sem eles não é possível haver sociedade. Em terceiro lugar, porque toma o caráter pretensamente socialista da revolução soviética e outras como prova empírica da impossibilidade de uma outra forma de sociabilidade e da inviabilidade da extinção do direito e da política. E, em último lugar, porque pressupõe que direito e política tenham a capacidade de controlar a dinâmica do capital (TONET, 2012, p. 68). 
A EDUCAÇ̃̃O EM DIREITOS HUMANOS DIANTE

DA ASCENSÃO DO "NOVO FASCISMO"

Não é objetivo, neste artigo, aprofundar em demasia as diferentes visões sobre direitos humanos. Em nosso ver, a visão liberal-democrática enxerga a necessidade de, diante de ondas conservadoras e fascistas contemporâneas, que negam os princípios básicos dessas conquistas históricas democráticas, aperfeiçoar o "sistema" ético-cultural para que tais fenômenos sejam minimizados. Voltando à Tonet (2002; 2005), essa visão toma os direitos como algo universal, quando na prática concreta não o são (são para determinadas classes); e não poderia deixar de ser diferente, numa sociedade "fundada" pelo modo de produção capitalista. Uma segunda crítica vai no mesmo sentido: esquece-se da dimensão econômica - no sentido das relações sociais de produção e suas implicações políticas e sociais - quando se pensa em cidadania e direitos humanos. Nesse sentido, os autores abaixo, cada um com suas especificidades no campo marxista, irão tencionar o debate sobre o fascismo e o conservadorismo contemporâneos, integrando esse debate à própria ascensão do neoliberalismo (ou o liberalismo econômico).

Assim, a partir da década de 1970, o funcionamento da economia passou por uma sucessão de transformações devido ao processo de transnacionalização do capital, incorporando novas características econômicopolíticas globais. O processo civilizatório e de produção alcançaram níveis mundiais, envolvendo de forma desigual "nações e nacionalidades, regimes políticos e projetos nacionais, grupos e classes sociais, economias e sociedades, culturas e civilizações" (IANNI, 1997a, p. 7). Assim:

Entre as categorias do pensamento político que parecem desafiadas pelos dilemas e horizontes que se abrem com a globalização estão: sociedade civil, Estado, partido político, sindicato, movimento social, opinião pública, povo, classe social, cidadania, soberania e hegemonia, entre outras. À medida que essas e outras categorias foram elaboradas com base na dinâmica da sociedade nacional, como emblema por excelência das ciências sociais, provavelmente elas pouco ou nada respondam às exigências da reflexão sobre a dinâmica da sociedade mundial. Sim, as relações, os processos e as estruturas de dominação, mais característicos da sociedade global, como novo emblema das ciências sociais, podem estar criando desafios radicais à política, como prática e teoria. Cabe reconhecer, desde o início, que está em curso uma crise generalizada do Estado-Nação (IANNI, 1997b, p.3)

Paralelamente a esse processo de reprodução do capital em ordem mundial, houve também a reprodução e criação de desigualdades, bem como carências e tensões que possibilitaram e possibilitam a manifestação de problemas de cunho sociais, econômicos e políticos, os quais exteriorizamse na forma de xenofobias, etnocentrismos, radicalismos, fundamentalismos e violências (IANNI, 1997a). Assim, a argumentação de lanni resume-se da seguinte maneira: as reconfigurações econômicas, políticas, sociais e culturais 
engendradas pelo capitalismo pós anos 1970 reavivam conflitos sociais e culturais diversos e abrem espaço para novas manifestações de racismo, xenofobia, preconceitos, dentre outros.

Nesta perspectiva, considera-se que a mundialização da produção e forças produtivas, ao mesmo tempo que fabrica diversidades, também fabrica desigualdades. Desse modo, é claro que tal processo globalizatório não torna as sociedades homogêneas, uma vez que fomenta a diversidade de perspectivas, bem como a multiplicidade dos modos de ser, a integração e diferenciação entre culturas e a pluralização de valores, tratando-se de uma nova realidade, que integra e recria singularidades, nacionalismos e identidades, revelando-se como um "caleidoscópio desconhecido" (IANNI, 1997a, p. 34).

Apenas a título de exemplo, pode-se citar o seguinte fenômeno econômico-social, o chamado processo de concorrência e competição entre trabalhadores, que se acirra diante da globalização:

\begin{abstract}
Hoje, muitas vezes ouvimos - na ideologia de concorrência nacional tantas vezes utilizada para canalizar a insatisfação de classe - que os trabalhadores americanos enfrentam uma maior concorrência por empregos com trabalhadores mexicanos, chineses, indianos etc. Em nossa opinião, isto não é um reflexo do aumento da concorrência - certamente não no sentido que este termo é usado em economia - mas do crescimento das corporações multinacionais monopolistas, que, através de seu grande número de afiliadas no exterior, seu ainda maior número de subcontratadas, e sua influência corruptora sobre governantes nacionais e executores de políticas, são hábeis em utilizar uma estratégia de dividir para reinar no que diz respeito aos trabalhadores do mundo. A concorrência entre trabalhadores é agravada com o crescimento da internacionalização do capital: eles são dois lados da mesma moeda. O resultado é uma intensificação mundial da taxa de exploração (e do grau de monopólio) (FOSTER; MCCHESNEY; JONNA, 2011, p.155).
\end{abstract}

Ainda que os autores citados estejam originalmente preocupados com as dinâmicas econômicas da concentração e monopolização de um capitalismo cada vez mais internacionalizado, é possível inferir, se nos aproximarmos dos argumentos de lanni, que esse acirramento da concorrência entre trabalhadores pode gerar um clima de instabilidade, intolerância e xenofobia para com imigrantes, por exemplo. É claro que não se pode reduzir esses problemas, unicamente, a essa dinâmica econômica, pois ele comporta dimensões culturais e políticas igualmente fortes.

Voltando ao debate, Löwy, de forma direta, desenvolveu uma interpretação acerca dos fenômenos do chamado novo conservadorismo e da ascensão deste novo fascismo. Segundo Löwy (2015), a chamada "transição" para o capitalismo global fora desastrosa, uma vez que a liderança de partidos liberais tornou possível a criação de condições propícias para o surgimento de ameaças de extremadireita. Assim, é neste contexto de exteriorização das diferenças e inexistência do 
ideal de tolerância que emergem perspectivas de cunho conservador e fascista, persistindo até os dias de hoje na forma de ideologia e utopia.

Sendo assim, estando intrinsecamente relacionados ao processo de homogeneização cultural forçada, bem como a fatores econômicos de crises que tendem a culpabilizar o papel que o Estado exerce na sociedade, o sucesso crescente da direita e extrema-direita constitui-se como um fenômeno fascista, não sendo apenas um efeito derivado de crises econômicas e do desemprego (LÖWY, 2015). O fascismo, nesta perspectiva, tem avançado de forma constante através da propagação de ideologias repressivas no âmbito da negação aos direitos humanos fundamentais, como o culto da violência policial, o estabelecimento da pena de morte e as intolerâncias para com as minorias sexuais, de forma a legitimar golpes militares que, para a ambas as vertentes ideológicas, devem ser consideradas na luta contra a corrupção (LÖWY, 2015). Recordando Bobbio (2007), o fascista assume o discurso relativo ao combate à corrupção de forma a alcançar o poder. Quando assim o faz, este não hesita em estuprar, torturar e roubar direitos. Para além da corrupção, o fascista acaba por praticar crueldade.

Nesta perspectiva, tais ideias acabam por contaminar parte significativa da burguesia, bem como da classe trabalhadora, a qual é vítima da manipulação por parte, principalmente, das grandes mídias de massa - como o rádio, a TV, as revistas e a internet - uma vez que apresentam de forma distorcida e parcial as notícias, naturalizando a desigualdade e incitando a população a concordar com práticas fascistas e ideais de legitimação da repressão dos trabalhadores, criminalização de movimentos sociais e o uso da força por parte do Estado (LÖWY, 2015; BARROCO, 2015).

No entanto, não podemos ignorar que o cenário histórico tem revelado uma crise de hegemonia das esquerdas e dos projetos socialistas de modo geral. É nesse contexto que o conservadorismo tem encontrado espaço para se reatualizar, apoiando-se em mitos, motivando atitudes autoritárias, discriminatórias e irracionalistas, comportamentos e ideias valorizadoras da hierarquia, das normas institucionalizadas, da moral tradicional, da ordem e da autoridade. Uma das expressões dessa ideologia é a reprodução do medo social (BARROCO, 2011, p. 210).

Com efeito, o discurso dominante neoconservador e fascista acaba por irradiar-se em instituições pautadas na forma de controle tecnocratas e sistemáticas, naturalizando e moralizando a criminalidade (BARROCO, 2015). O fascismo, desse modo, configura-se em um composto combinável do conservadorismo e da direita radical, estando unidos por inimigos em comum, de modo a buscar por uma "energização e purificação" da Nação, independentemente do preço a ser pago para se alcançar tal objetivo (PAXTON, 2007). Esse fascismo pluralista acaba por assumir uma forma nunca precedida anteriormente, o que pressupõe que alternativas sejam criadas a fim de contê-lo. 
Faz-se necessário destacar que essas forças políticas organizadas configuram-se de forma difusa e diferenciada em relação ao "fascismo clássico", constituindo-se como uma versão complexa deste tipo de fascismo (FERNANDES, 1981). Nesse sentido, é interessante trazer à tona os argumentos de Florestan Fernandes que, já em 1981, antecipava, de certa forma, o florescimento do fascismo nas ditaduras capitalistas e no centro das democracias liberais burguesas. Desse modo,

Não só ainda existem regimes explicitamente fascistas em vários países; uma nova manifestação do fascismo tende a tomar o corpo: através de traços e mesmo de tendências mais ou menos abertas ou dissimuladas, a versão industrialista "forte" da democracia pluralista contém estruturas e dinamismos fascistas. Na verdade, a chamada "defesa da democracia" somente modificou o caráter e a orientação do fascismo, evidentes em rigidez política de hegemonia burguesa, no uso do poder político estatal para evitar ou impedir a transição para o socialismo, na tecnocratização e militarização das "funções normais" do Estado capitalista (FERNANDES, 1981, p. 15).

Na América Latina, segundo Florestan, a situação se complexifica diante de uma situação de dependência econômica, política e cultural principalmente pelo imperialismo norte-americano no continente. Nesta perspectiva, o fascismo encontra-se também no nível do Estado, contudo, de modo silencioso, pressupondo o uso da opressão social e da repressão política por parte deste, bem como a exacerbação do uso autoritário e totalitário da luta de classes, ao invés da doutrinação de movimentos de massa. Em vista disso, constitui-se como uma força substancialmente contra-revolucionária, visando empregar uma guerra civil em dois níveis diferentes, conforme nos é apresentado por Fernandes (1981, p. 17):

$1^{\circ}$ contra a democratização como um processo social de mudança estrutural (por exemplo, quando ela ameaça a superconcentração da riqueza, do prestígio e do poder); ou seja, ele se ergue, de modo consciente, contra a "revolução dentro da ordem"; $2^{\circ}$ contra todos os movimentos socialistas, qualificados como revolucionários - portanto, ele também procura barrar a "revolução contra a ordem existente.

Em outras palavras, essa nova configuração do fascismo está no seio da democracia liberal - com destaque aos países dependentes e periféricos - a fim de reprimir qualquer tentativa de mudança mais radical nas relações econômicas, sociais, políticas e culturais das nações: o pensamento ultraconservador e fascista - com um nacionalismo conservador específico à história dos países latino-americanos - eleva-se mediante à defesa das relações de produção e exploração dominantes, negando, contraditoriamente, as 
próprias bases ideais da democracia liberal da qual foram constituídas. Nesse sentido, o fascismo corresponde às duas funções de auto-privilegiamento e autodefesa por parte das "classes ameaçadas", objetivando o desenvolvimento com vistas a assegurar uma estabilidade política no âmbito da periferia, isto é, objetiva um "desenvolvimento com segurança" que coincide com os interesses reacionários, conservadores e contra-revolucionários da burguesia (FERNANDES, 1981, p. 18).

Consequentemente, o caráter fascista corporifica-se e atualiza-se nas ações e projetos políticos que reproduzem constantemente o totalitarismo de classe e a "defesa da ordem" através de meios reacionários e violentos. Em suma, não podemos assumir que o fascismo tenha sido extinto em sua totalidade, uma vez que tornou-se parte intrínseca das tecnoestruturas militares e civis no âmbito das sociedades capitalistas. Esse fenômeno, contudo, operaria de modo silencioso e dissimulado, sendo demasiado "racional" e "eficaz", bem como compatível com a democracia, assumindo uma nova dimensão dinâmica que visa combater o "fantasma da ameaça comunista, de novas Cubas" (FERNANDES, 1981, p. 33).

Voltando a Lowy (2015) e Paxton (2007), esse fenômeno ainda é vivo e tende a tornar-se mais forte a depender do contexto. De forma mais concreta, a constituição de um cotidiano monitorado por parte do aparato estatal pode ser exemplificado através do controle da comunicação de massa, a opressão e neutralização da oposição, bem como parlamentos simbólicos como é o caso da "bancada BBB" que domina o Congresso brasileiro (LÖWY, 2015).

Cabe destacar, a fim de complexificar o argumento, que a escalada do conservadorismo e do novo fascismo, ainda na perspectiva alinhado ao marxismo, está relacionada com o próprio fortalecimento do neoliberalismo. Em termos gerais, o neoliberalismo representa a retomada dos ideais do liberalismo clássico no sentido econômico: "um ataque apaixonado contra qualquer limitação dos mecanismos de mercado por parte do Estado, denunciadas como uma ameaça letal à liberdade" (ANDERSON, 1995). Em teoria, no que se refere a atuação do Estado, a ideologia recomenda que se deve fortalecer os direitos individuais de propriedade privada e o regime de direito para garantir o funcionamento do livre mercado (HARVEY, 2013). As ações estatais, nesse sentido, são direcionadas a privatizações e a eliminação de entraves burocráticos que interferem na eficiência e produtividade econômica.

Porém, na prática, e aí encontra-se a contradição dessa ideologia, o neoliberalismo vê a democracia com desconfiança, pois considera que a população, através do sistema político, possa querer intervir na livre iniciativa e limitar o livre mercado. Em consequência, tendem a apoiar uma governança realizada por técnicos e elites e a minar as estruturas democráticas que permitam as reivindicações por direitos políticos e sociais (HARVEY, 2013;

2Bancada do Boi, Bíblia e Bala, ou "bancada BBB", consiste em um termo pejorativo que diz respeito a parlamentares ruralistas, evangélicos e defensores de propostas ligadas à máxima violência por parte do poder estatal alinhadas à direita e extrema-direita política brasileira, bem como ao conservadorismo. 
ANDERSON, 1995). Com efeito, tal rejeição revelou contradições importantes, como o fortalecimento do Estado para salvaguardar o mercado em detrimento dos direitos políticos e sociais (HARVEY, 2013; ANDERSON, 1995). Com efeito, nesse processo, o Estado precisa agir com violência para coibir qualquer tentativa de resistência ou de superação das desigualdades provocadas pela implementação de ações apoiadas nessa ideologia.

É aí que, argumenta-se, o neoliberalismo e os movimentos ultraliberais contemporâneos ${ }^{3}$ se apresentam, contraditoriamente, no plano político, como conservadores e, a depender do contexto, com traços desse novo fascismo que acabamos de caracterizar. É claro que o neoliberalismo assumiu e assume diversas facetas a depender do contexto, engendrando diversas reações contrahegemônicas ${ }^{4}$. Porém, no geral, essa ideologia não só contribuiu para o redesenho da atuação do Estado na economia, na sociedade e na política, como também para fortalecer, no plano cultural, os ideais de mérito individual, exacerbandose o individualismo enquanto mote de convivência (HARVEY, 2013). Nesse bojo, é preciso recrudescer a repressão a movimentos sociais e minar os direitos sociais e políticos historicamente constituídos, apelando-se para, no plano político, o alinhamento ao pensamento autoritário e conservador.

Em outra perspectiva teórica, mas corroborando com o argumento anterior, o neoliberalismo, no plano político, se distingue do liberalismo clássico americano justamente por atacar o Estado keynesiano ou de bem-estar e toda organização liberal democrática oriunda desse padrão, inclusive a que deu origem a parte dos direitos humanos fundamentais, aproximando-se da tradição mais conservadora no tocante às políticas sociais (DRAIBE, 1993). Assim:

Esta ideologia dominante [o neoliberalismo] é principalmente composta por proposições práticas e, no plano conceitual, reproduz um conjunto heterogêneo de conceitos e argumentos, reinventando o liberalismo mas introduzindo formulações e propostas muito mais próximos do conservadorismo político e de uma sorte de darwinismo social distante pelo menos das vertentes liberais do século XX (DRAIBE, 1993, p. 86).

Clarifica-se que o pensamento conservador e o novo fascismo não são o mesmo fenômeno e nem se pode fazer uma relação determinista entre conservadorismo e fascismo (visto que um não implica no outro necessariamente). Porém, neste ponto, o argumento levantado pelos autores considerados aqui - a hipótese - é de que todas estas mudanças ocorridas no mundo a partir da década de 1970, destacando-se aí o globalismo e o neoliberalismo, promove e fortalece o conservadorismo e possibilita o florescimento, a depender do contexto e da conjuntura, do novo fascismo.

3 Alguns estudos vêm discutindo a ascensão de organizações ultraliberais - as chamadas Think Tanks liberais, como o Movimento Brasil Livre - que atuam na sociedade civil a fim de promover essa ideologia e, além do mais, restringir nos espaços a livre manifestação do pensamento de esquerda. Para isso, ver Vieira (2006) e Oliveira e Machado (2016). Exemplo interessante é a atuação do "Escola sem Partido".

4 Para ver discussão sobre neoliberalismo na América Latina e no Brasil, ver: Anderson (1995), Fagnani (1997), Draibe (1993), Ibarra (2011). 
A EDUCAÇÃO EM DIREITOS HUMANOS DIANTE

DA ASCENSÃO DO "NOVO FASCISMO"

É aí que, frisa-se, está uma das contradições da democracia liberal burguesa apontada pelos autores anteriores. Nesse ponto, fica claro também a erosão da própria base que sustentou a criação e propagação do conjunto dos direitos humanos historicamente constituídos na ordem liberal - atrelados a um capitalismo do tipo fordista e a um Estado de bem-estar social (ao menos na Europa ocidental e nos EUA) que emergiram a partir da segunda guerra.

Antes de passarmos ao próximo tópico, convém pontuar que autores pertencentes a outras perspectivas teóricas também apontam para a necessidade de se pensar esses fenômenos como resultantes do próprio arranjo democrático e econômico constituído atualmente. Boaventura de Souza Santos (1998), por exemplo, identifica uma crise no chamado contrato social, assentado em critérios de inclusão e exclusão de grupos sociais, diante das mudanças econômicas, políticas, sociais e culturais apontadas anteriormente. Assim, Santos (1998) considera que apesar de convivermos com base em ideais democráticos, aspirando uma sociedade livre e com justiça social, estamos na verdade vivendo em regimes autoritários sob um verniz democrático, isto é, vivemos em sociedades socialmente fascistas. Para esse autor, há uma crise no contrato social, justamente porque os mecanismos de exclusão social (aí incluindo-se os econômicos, políticos, culturais, morais) estão predominando sobre os de inclusão. Destaca-se, pois, a emergência do "fascismo societal", o qual não pode ser atrelado ao fascismo dos anos trinta e quarenta, mas sim a um fascismo que nunca existiu, um "fascismo pluralista". De acordo com Santos (1998), o "fascismo pluralista" pode assumir diferentes formas, são elas: o fascismo do apartheid social; o fascismo do Estado paralelo; o fascismo paraestatal; o fascismo contratual; o fascismo territorial; o fascismo populista; o fascismo da insegurança e; por fim, o fascismo financeiro 5 .

Desse modo, ressalta a necessidade de um novo contrato social, o que significaria a transformação de um Estado Nacional em movimento social, possibilitando a coordenação de instâncias de cunho participativo, de forma a articular redes e fluxos no interior dessa nova organização. Ante isso, Santos (1998, p. 30) afirma que:

Há, pois, que buscar alternativas de sociabilidade que neutralizem ou previnam esses riscos e abram caminho a novas possibilidades democráticas. Não se trata de tarefa fácil dado que a desregulação social provocada pela crise do contrato social é tão profunda que acaba por desregular as próprias resistências aos factores de risco e as exigências emancipatórias que lhe dariam sentido. (...) A nível muito geral, essa exigência traduz-se na reconstrução ou reinvenção de um espaço-tempo que favoreça e promova a deliberação democrática.

Portanto, buscou-se, neste tópico, explorar uma perspectiva que busca explicar

o novo fascismo e o avanço de um conservadorismo cada vez mais radicalizado 5 Não vamos, de acordo com os objetivos deste artigo, aprofundar na definição destes tipos de fascismo pontuados por Boaventura. 
justamente nas contradições das democracias liberais burguesas. Adotou-se, também, uma perspectiva mais ampla do fenômeno, entendendo que as especificidades e localidades são importantes à análise concreta. Nesse sentido, a Educação em Direitos Humanos coloca-se como alternativa a ser debatida. Porém, de acordo com o que foi exposto, deriva-se a pergunta central do artigo: em que medida a EDH pode contribuir ao combate ao novo fascismo e que medida não pode?

\section{A educação em direitos humanos enquanto alternativa local e limitada}

Neste tópico, buscou-se definir o que é a EDH, como ela se caracteriza e, de forma a aproximar o debate à realidade nacional, descrever como ela se concretiza nos sistemas educacionais - e, sobretudo, no ensino superior. Com isso, na conclusão do artigo, foi possível explorar a intersecção do debate realizado no tópico anterior com o que foi apresentado aqui. Desse modo, reconhecendo a EDH enquanto um dos direitos fundamentais, constituindo-se como uma consequência da decadência das ditaduras militares ao final dos anos 1970, assim como do processo de redemocratização sucedido nos países da América Latina, fundamenta-se por meio do respeito, defesa e promoção do conjunto de direitos que visam garantir a dignidade da pessoa humana, apresentando ferramentas e elementos que possam torná-los efetivos (MAGENDZO, 2006).

Essa prática educativa visa intervir de forma objetiva na formação de sujeitos sociais enquanto cidadãos, baseando-se na transferência de valores através de uma educação permanente, continuada e global. Isto é, trata-se de uma formação baseada no respeito à dignidade da pessoa humana, estando orientada para "a mudança no sentido de eliminar tudo aquilo que está enraizado nas mentalidades por preconceitos, discriminação, não aceitação dos direitos de todos, não aceitação da diferença" (BENEVIDES, 2003, p. 1). Tal processo dá-se através da produção e disseminação de conhecimentos, os quais devem estar presentes no ensino, na pesquisa e na extensão, visando eliminar tais deturpações e visões limitadas no âmbito do discurso acerca dos direitos humanos fundamentais.

De acordo com Marilena Chauí (2006), a EDH não deve ser reduzida à transmissão de informações; ao contrário, deve consistir em uma tarefa de mudança cultural que visa formar os discentes para além da habilitação para o mercado de trabalho, uma vez que, sendo a educação um direito do cidadão, esta deve tornar-se no sentido profundo de sua origem uma formação para a cidadania e da cidadania, assumindo um caráter construtivo do conhecimento e civilizatório de modo que os discentes declarem uma postura contrária à violência social, política, econômica e cultural. Trata-se, em outra perspectiva, da transição entre o "conhecimentocomo-regulação" para um "conhecimento-como-emancipação", isto é, "uma outra epistemologia para a qual o ponto de ignorância é o colonialismo e o ponto de saber é a solidariedade" (SANTOS, 1998, p. 31). 
A EDUCAÇ̃̃O EM DIREITOS HUMANOS DIANTE

DA ASCENSÃO DO "NOVO FASCISMO"

Nesse sentido, cabe ressaltar três dimensões que perpassam a EDH em seu horizonte de sentido: a primeira delas refere-se à formação de sujeitos de direitos, de forma a articular as perspectivas da ética, político-social e práticas concretas; a segunda dimensão diz respeito à oportunização no processo de "empoderamento", no sentido de proporcionar possibilidades e demonstrar a potência de cada ator social, especialmente àqueles que historicamente possuem menos poder nas decisões e processos coletivos; e a terceira dimensão refere-se à construção de sociedades democráticas, de forma a "educar para o nunca mais", isto é, resgatar a memória histórica dos direitos humanos, rompendo com a cultura do silêncio e da impunidade (CANDAU, 2008).

Desse modo, ao obter maior força através do discurso democrático, a EDH no Estado brasileiro passou a ser refletida na própria Constituição Federal, bem como está presente na Lei de Diretrizes e Bases da Educação Nacional e demais documentos oficiais do Governo Federal, em especial no Plano Nacional de Educação em Direitos Humanos (PNEDH) e nas Diretrizes Nacionais para a Educação em Direitos Humanos. Essas políticas incorporam diversos elementos de instrumentos internacionais dos quais o Brasil é signatário, configurando-se como políticas educacionais direcionadas para a formação de sujeitos de direitos (BRASIL, 2012).

No âmbito do PNEDH (BRASIL, 2007, p. 25), esse modelo educativo apresenta-se como um processo multidimensional e sistemático, articulandose com base nos seguintes princípios:

\begin{abstract}
a) apreensão de conhecimentos historicamente construídos sobre direitos humanos e a sua relação com os contextos internacional, nacional e local; b) afirmação de valores, atitudes e práticas sociais que expressem a cultura dos direitos humanos em todos os espaços da sociedade; c) formação de uma consciência cidadã capaz de se fazer presente em níveis cognitivo, social, ético e político; d) desenvolvimento de processos metodológicos participativos e de construção coletiva, utilizando linguagens e materiais didáticos contextualizados; e) fortalecimento de práticas individuais e sociais que gerem ações e instrumentos em favor da promoção, da proteção e da defesa dos direitos humanos, bem como da reparação das violações.
\end{abstract}

Sendo assim, a EDH manifesta-se como um processo educativo que delineia o reconhecimento e fortalecimento do debate acerca dos direitos humanos, tornandose necessária sua incorporação em todos os níveis educacionais. Tal premissa apresenta-se diretamente no âmbito das Diretrizes Nacionais para a Educação em Direitos Humanos (BRASIL, 2012), a qual considera que o objetivo central desse tipo de formação deve orientar as instituições e sistemas de ensino no campo do planejamento e desenvolvimento de ações de Educação em Direitos Humanos.

No âmbito do ensino fundamental e médio, considera-se que essa temática deva ser realizada de modo interdisciplinar e transversal nas diretrizes curriculares, bem como integre os conteúdos, metodologias e avaliações, de forma a fomentar 
a discussão de temas diversos através do desenvolvimento de uma pedagogia participativa, com vistas a tornar tal processo educativo um elemento expressivo na formação dos estudantes (FERNANDES, PALUDETO, 2010).

Nesta perspectiva, tendo em consideração que as Instituições de Ensino Superior (IES) são detentoras de um lugar privilegiado, concebemos a EDH como um dos compromissos sociais da universidade pública, uma vez que esta pode contribuir com a produção e disseminação de conhecimentos para o desenvolvimento humano. Desse modo, considerando que o compromisso social da universidade é alvo de diferentes interpretações, reconhece-se a importância social da universidade enquanto geradora de uma cultura pautada nos princípios relativos aos direitos humanos, uma vez que, assim como nos apresenta Dias Sobrinho (2014, p. 657),

Só é digna de nomear-se universidade a instituição que produz e dissemina o conhecimento como direito social e bem público, isto é, como algo essencial e imprescindível à formação de sujeitos capazes de participar criativa e criticamente da sociedade.

Assim, ainda de acordo com o PNEDH (BRASIL, 2007), os pilares da universidade devem estar alinhados à sua missão de cunho educacional, social e institucional. Em outras palavras, entende-se que seu comprometimento deve estar atrelado às demandas sociais; criando, disseminando e articulando conhecimentos acadêmicos e populares, a fim de possibilitar transformações sociais através de uma formação cidadã, de forma a auxiliar e orientar ações coletivas.

A universidade, nesse sentido, não deve possuir um caráter estritamente utilitarista, "abrindo mão" de sua autonomia, de seu modo de organização e finalidades. Esse novo paradigma, entretanto, reflete a subordinação e a submissão que a Educação Superior adotou em relação a produção científica e tecnológica favorável ao mercado, legitimando a visão utilitarista do conhecimento (DIAS SOBRINHO, 2014).

Considera-se, portanto, que a incorporação dessa perspectiva de ensino nas IES deve compartilhar dos seguintes princípios:

a) a universidade, como criadora e disseminadora de conhecimento, é instituição social com vocação republicana, diferenciada e autônoma, comprometida com a democracia e a cidadania; b) os preceitos da igualdade, da liberdade e da justiça devem guiar as ações universitárias, de modo a garantir a democratização da informação, o acesso por parte de grupos sociais vulneráveis ou excluídos e o compromisso cívico-ético com a implementação de políticas públicas voltadas para as necessidades básicas desses segmentos; c) o princípio básico norteador da educação em direitos humanos como prática permanente, contínua e global, deve estar voltado para a transformação da sociedade, com vistas à difusão de valores democráticos e republicanos, ao fortalecimento da esfera pública e à construção de projetos coletivos; 
d) a educação em direitos humanos deve se constituir em princípio ético-político orientador da formulação e crítica da prática das instituições de ensino superior; e) as atividades acadêmicas devem se voltar para a formação de uma cultura baseada na universalidade, indivisibilidade e interdependência dos direitos humanos, como tema transversal e transdisciplinar, de modo a inspirar a elaboração de programas específicos e metodologias adequadas nos cursos de graduação e pós-graduação, entre outros; f) a construção da indissociabilidade entre ensino, pesquisa e extensão deve ser feita articulando as diferentes áreas do conhecimento, os setores de pesquisa e extensão, os programas de graduação, de pós-graduação e outros; g) o compromisso com a construção de uma cultura de respeito aos direitos humanos na relação com os movimentos e entidades sociais, além de grupos em situação de exclusão ou discriminação; h) a participação das IES na formação de agentes sociais de educação em direitos humanos e na avaliação do processo de implementação do PNEDH (BRASIL, 2007, p. 38-39).

Dessa forma, a Educação em Direitos Humanos no Ensino Superior deve ser considerada como uma estratégia para a construção de uma cultura pautada nos princípios relativos aos direitos humanos, fomentando uma visão crítica e uma conduta emancipadora por parte dos discentes através da introdução dessa temática em atividades de ensino, pesquisa e extensão e, ao mesmo tempo, sendo uma das formas possíveis para que a universidade possa cumprir com seu compromisso social, bem como uma das formas locais de superação da ascensão do fascismo.

Reiterando tal perspectiva, as Diretrizes Nacionais para a Educação em Direitos Humanos apresenta que as IES devem ser responsáveis pela formação de profissionais que respeitam e promovem os direitos humanos, devendo ser incorporada tal concepção, de modo transversal, nos Programas Pedagógicos dos Cursos (PPCs), bem como nos projetos de pesquisa e extensão (BRASIL, 2012). No que diz respeito à incorporação da perspectiva da EDH nos PPCs, esta poderá ocorrer por meio de diferentes formas:

a) pela transversalidade, por meio de temas relacionados aos Direitos Humanos e tratados interdisciplinarmente; b) como um conteúdo específico de uma das disciplinas já existentes no currículo escolar; c) de maneira mista, ou seja, combinando transversalidade e disciplinaridade (BRASIL, 2012, p. 12).

No âmbito da pesquisa, esfera em que a universidade pode contribuir de forma mais específica, a EDH deve ser incorporada por meio de políticas de incentivo à realização de estudos e investigações, de forma a criar núcleos de estudos e pesquisas com atuação nos seguintes princípios: dignidade humana; laicidade do Estado; igualdade de direitos; democracia na educação; reconhecimento e valorização das diferenças e das diversidades; 
transversalidade, vivência e globalidade; e sustentabilidade socioambiental (BRASIL, 2012). Desse modo, através de um diálogo interdisciplinar, a universidade seria capaz de incentivar e fomentar a produção científica no campo dos direitos humanos (TOSI, 2005; CARDOSO, 2016; PIOVESAN, 2008), bem como contribuir para uma transformação cultural, intensificando a luta contra as violações de direitos e o reconhecimento de comunidades e grupos socialmente excluídos (LOURENÇO; AFONSO, 2015).

Na modalidade da extensão, considerada como a porta de entrada da esfera dos direitos humanos na universidade, deve-se ir muito além do que uma prestação de serviços à comunidade, de forma a assumir um caráter educativo amplo, contribuindo com ações voltadas para os segmentos sociais "subalternos", gerando "uma cultura pela paz e a democracia (...) capaz de sustentar a construção de um Estado democrático de direito" (TOSI, 2005, p. 29). Reconhece-se também, em âmbito da Política Nacional de Extensão (FORPROEX, 2012), que a universidade deve apoiar o Estado na elaboração, implementação e execução de políticas públicas. Para isso, a universidade, segundo essa Política, deveria priorizar suas ações de extensão em alguns eixos temáticos mais amplos. Um desses eixos, justamente, são os Direitos Humanos. Com efeito, reconhecese a importância e o compromisso social da universidade, via extensão, na execução de ações que promovam e disseminem os Direitos Humanos.

Destaca-se, nesse sentido, a importância das IES na formação de cidadãos éticos e comprometidos com a defesa dos direitos humanos (BRASIL, 2012). Desse modo, através da relação entre teoria e prática, a EDH parte de uma perspectiva interdisciplinar e transversal, sendo compreendida por intermédio da integração entre diferentes áreas do conhecimento. A nosso ver, a EDH no âmbito do Ensino Superior - através da produção de conhecimento e da extensão - seria uma das principais ações que, ao mesmo tempo, vão ao encontro do Plano Nacional de Extensão (2012), do Plano Nacional de Educação em Direitos Humanos (2007) e, também, das Diretrizes Nacionais para a Educação em Direitos Humanos (BRASIL, 2012), bem como constitui em uma forma de minimizar e conter a crescente onda conservadora e fascista que permeiam a democracia moderna.

Contudo, reconhece-se alguns desafios perante a incorporação dessa prática educativa. De acordo com Candau e Sacavino (2008), o primeiro deles diz respeito à desconstrução da visão do senso comum acerca dos direitos humanos. Esse desafio relaciona-se à visão deturpada de que os direitos humanos consistem nos "direitos à proteção dos bandidos", bem como está associada a ideia de que estes abrangem apenas os direitos relativos à liberdade. $O$ segundo desafio diz respeito à apropriação de uma concepção de educação em direitos humanos e esclarecimento do que se pretende atingir em cada situação concreta (CANDAU; SACAVINO, 2008). O horizonte de sentido da Educação em Direitos Humanos deve ser compreendido a partir da formação de sujeitos de direitos, empoderamento de atores sociais e o resgate 
da memória histórica dos direitos humanos, contornando a visão polissêmica que perpassa sobre este debate.

O terceiro entrave refere-se à articulação de ações de sensibilização e de formação. Este, por sua vez, concerne à associação de ações de curta duração com os programas de formação destinados a possíveis multiplicadores, de forma a investir de modo mais intenso nestes programas, difundindo o PNEDH, bem como permitindo que a afirmação dos direitos humanos penetre nos diferentes âmbitos das sociedades. Para tanto, a introdução da EDH deve ser realizada desde a formação inicial dos educadores de forma continuada e permanente (CANDAU; SACAVINO, 2008). Nesta perspectiva, driblar a capacitação docente para o ensinamento dos direitos humanos consiste em um dos principais desafios a ser superado (SALVIOLI, 2009).

Demais desafios presentes no âmbito da universidade também devem ser considerados, como por exemplo a dificuldade de se incorporar a EDH para além dos cursos de Direito, visto que a bibliografia consultada aponta a necessidade da transversalidade da temática diante dos currículos e das pesquisas de todas as áreas do conhecimento. Verifica-se também a debilidade relativa da extensão enquanto função universitária, incluindo-se à dificuldade em se praticar a indissociabilidade e a inter, trans e multidisciplinaridade requisitos exigidos para qualificar a prática da EDH na universidade, bem como os processos de privatização do ensino superior e mercantilização da universidade pública ${ }^{6}$, que ofereceriam entraves à uma formação e pesquisa críticas e comprometidas com as classes sociais excluídas, e, conectados a isto, a própria dificuldade em se democratizar o acesso à universidade.

Portanto, este tópico buscou caracterizar a EDH para que se possa discutir, na conclusão do artigo, suas potencialidades e limites.

\section{Conclusão}

Este artigo buscou debater a Educação em Direitos Humanos no âmbito acadêmico enquanto alternativa local para a superação da ascensão do fascismo na democracia moderna. Reconhece-se, portanto, que o fascismo adquiriu novas configurações, estando impregnado de forma difusa e não declarada tanto no âmbito do Estado quanto em movimentos caracterizados como de direita e extrema-direita, estando intrinsecamente ligado à configuração do sistema econômico global.

Por outro lado, a Educação em Direitos Humanos, reconhecida como um direito fundamental, surge com força, a partir do final dos anos 1970 e início dos anos 1980, no processo de redemocratização ocorrido nos países latinoamericanos. AEDH, como visto anteriormente, não se trata apenas da transferência de conhecimentos, mas está pautada em uma perspectiva de mudança cultural. 6 Nesse aspecto, apresenta-se o chamado capitalismo acadêmico, caracterizado pelo fortalecimento dos discursos acerca do empreendedorismo e inovação nas universidades e por maior engajamento na comercialização do conhecimento e pela busca por autofinanciamento diante da diminuição ou estagnação dos recursos públicos às universidades (DIAS; SERAFIM, 2015). 
Trata-se, nesse sentido, de uma formação que está fundamentada no âmbito do respeito à dignidade humana, na formação de sujeitos de direitos, de forma a articular as perspectivas da ética, político-social e práticas concretas, no processo de empoderamento de cada ator social. Nesse horizonte, tal processo educativo deve ser incorporado nas instituições de educação básica e educação superior, como aponta os documentos federais analisados.

Destaca-se que, na tentativa de contrastar as causas apresentadas relativas ao fortalecimento do conservadorismo e do fascismo com as soluções apresentadas pela EDH, que o processo educativo apresentado relativo a EDH não deve ser considerado enquanto única alternativa, uma vez que não é suficientemente capaz de transformar a situação social e econômica daqueles que se encontram em situações subalternas, constituindo-se como uma das formas de superação que integram a própria democracia burguesa.

Dessa forma, é possível considerar a Educação em Direitos Humanos (EDH) enquanto uma alternativa de superação do cenário apresentado anteriormente; porém, acaba constituindo-se enquanto um processo educativo local e limitado, uma vez que, apesar de propor uma mudança cultural no âmbito do respeito e garantia dos direitos humanos fundamentais, reconhecesse que sua incorporação exige uma predisposição por parte daqueles que consideram que a própria educação deve se constituir como uma ferramenta de emancipação, de forma a superar a visão restrita relativa à educação com vistas ao mercado de trabalho.

Além do mais, a EDH está em processo de implementação e, com efeito, limita-se por não ser satisfatoriamente integrada nos sistemas e ensino em geral. Contudo, considerando-se os fatores estruturais apontados no primeiro tópico deste artigo, além dos aspectos socioculturais e preconceitos diversos que inibem a plena implementação da EDH, o Estado encontra-se com dificuldades em garantir direitos sociais, muito por conta de seu "enxugamento" e de sua "condição neoliberal". Nesse sentido, a EDH limita-se também no que diz respeito à sua efetiva implementação no sistema público de ensino.

O caráter local e limitado da EDH também pode ser visualizado, em âmbito teórico, porque ela não toca nos problemas estruturais apontados pelos autores anteriores (do primeiro tópico), limitando-se justamente por ser fruto histórico das conquistas de direitos nas democracias liberais burguesas. Em outras palavras, deve-se considerar também que a EDH é limitada pela sua própria natureza, uma vez que se encontra vinculada à dinâmica da democracia liberal burguesa, não sendo possível atribuir somente à educação e à cultura a solução única para combater a ascensão do fascismo, isto é, outras dimensões devem ser consideradas em tal processo, como é o caso do sistema econômico global.

Tem-se, assim, as seguintes limitações integradas entre si: I. a crença na efetividade do processo educativo pautado em uma mudança de valores que pudessem combater os resquícios das ideologias que negam as construções históricas dos direitos humanos, negligenciando, em alguma medida, outros 
A EDUCAÇ̃̃O EM DIREITOS HUMANOS DIANTE

DA ASCENSÃO DO "NOVO FASCISMO"

fatores de ordem objetiva; II. as ações de EDH empreendidas por instituições educacionais - ou por instituições diversas - possuem impacto e objetivo local, sendo que os fenômenos apresentados no primeiro tópico, ainda que localmente contextualizados, possuem uma amplitude causal mais ampla e estrutural; III. as dificuldade de se fortalecer - em âmbito do próprio investimento estatal em educação pública - as políticas públicas que estimulem a EDH, dificuldades originadas (não somente, diga-se) por condicionantes estruturais afetos à lógica neoliberal, sobretudo em países dependentes; IV. e, finalmente, pelo fato de que a EDH forma-se, historicamente, no próprio seio da democracia liberal burguesa, sendo limitada justamente por não visualizar as contradições existentes nesses sistemas políticos e econômicos que engendram a ascensão do novo fascismo.

Em suma, cabe destacar, apesar das limitações apontadas, que a EDH se constitui enquanto uma alternativa concreta e potencial à se resistir aos avanços dos discursos e ações de ódio, racismo, xenofobia, "ultra conservadorismos" diversos e, também, à inibição da ascensão do novo fascismo. Cabe clarificar, também, que os fenômenos aqui debatidos possuem outras causas complexas e devem ser tomados em suas manifestações concretas, específicas e contextualizadas. O que buscou-se fazer, neste artigo, foi recortar e selecionar uma gama de argumentos que julgou-se importantes - inclusive enquanto uma visão alternativa e não hegemônicas - para se debater os problemas apresentados procurando oferecer, nesse processo.

\section{Referências}

ANDERSON, Perry. Balanço do neoliberalismo. In: Born, Atílio. Pós-neoliberalismo: as políticas sociais e o Estado democrático. Rio de Janeiro: Paz e Terra, p. 9-23, 1995.

BARROCO, M. L. Barbárie e neoconservadorismo: os desafios do projeto ético-político. Serv. soc. soc, n. 106, p. 205-218, 2011.

BEETHAN, D. Human rights as a model for cosmopolitan democracy. In: D. Archibugi, D. Held \& M. Kohler (Eds.). Reimagining political community: studies in cosmopolitan democracy. Cambridge: Polity Press. 1998.

BENEVIDES, M. V. Educação em direitos humanos: de que se trata?. Formação de Educadores. Desafios e Perspectivas. São Paulo: UNESP, 2003

$\mathrm{BOBBIO}$, Norberto. Do fascismo à democracia: os regimes, as ideologias, os personagens e as culturas políticas. Elsevier, 2007.

BRASIL. Ministério da Educação. Conselho Nacional de Educação. Diretrizes Nacionais para a Educação em Direitos Humanos. Brasília, 2012.

BRASIL. Secretaria Especial dos Direitos Humanos da Presidência da República. Plano Nacional de Educação em Direitos Humanos. Brasília: SEDH/PR. 2007.

CANDAU, V. M. Educação em Direitos Humanos e estratégias metodológicas. 2008.

CANDAU, Vera; SACAVINO, Susana. Educação em direitos humanos no Brasil: ideias-força e perspectivas de futuro. In: MAGENDZO, Abraham (org.). Pensamiento e ideas-fuerza de la educación en derechos humanos en Iberoamérica. Santiago, Chile: OIE/Orealc/Unesco, p. 68-83, 2008.

CARDOSO, Clodoaldo Meneguello. Valores ético-políticos na formação Universitária. CARDOSO, C. M. (Org.).

Universidade, poder e direitos humanos. São Paulo: Cultura Acadêmica, 2016. 
CHAUÍ, M. Congresso Interamericano de Educação em Direitos Humanos. Conferência de abertura. Brasília, 30 de agosto de 2006

CORTEZ EDITORA. Palestra: Michel Löwy e Maria Lucia Barroco, 03 jul. 2015. Disponível em: <https://www. youtube.com/watch?v=8T0kLQTKB7A\&feature=share>. Acesso em 09 jun. 2017.

DALLARI, Dalmo de Abreu. O Brasil rumo à sociedade justa. In: SILVEIRA, Rosa Maria Godoy, et al. Educação em Direitos Humanos: fundamentos teórico-metodológicos. Brasília: Secretaria Especial dos Direitos Humanos, p. 29-49, 2010.

DIAS, R. B.; SERAFIM, M. P. Comentários sobre as transformações recentes na universidade pública brasileira. Avaliação: Revista da Avaliação da Educação Superior, vol. 20, n.2, 2015.

DIAS SOBRINHO, J. Universidade e novos modos de produção, circulação e aplicação do conhecimento. Avaliação: Revista da Avaliação da Educação Superior, v. 19, n. 3, 2014.

DRAIBE, Sônia Maria. As políticas sociais e o neoliberalismo - Reflexões suscitadas pelas experiências latinoamericanas. Revista USP, n. 17, p. 86-101, 1993.

FAGNANI, E. Política social e pactos conservadores no Brasil: 1964/92. Economia e Sociedade, n. 8, p.183-238, 1997.

FERNANDES, A. V. M.; PALUDETO, M. C. Educação e direitos humanos: desafios para a escola contemporânea. Cadernos CEDES, p. 233-249, 2010.

FERNANDES, Florestan. Poder e contrapoder na América Latina. Rio de Janeiro, RJ: Zahar, 1981.

FORPROEX. Política Nacional de Extensão Universitária. 2012. Disponível em: <https://www.ufmg.br/proex/ renex/documentos/2012-07-13-Politica-Nacional-de-Extensao.pdf>. Acesso em 04 mai. 2017.

FOSTER, J. B.; MCCHESNEY, R.; JONNA, J. A Internacionalização do Capital Monopolista. Cadernos de Ciências Sociais Aplicadas, n. 11, p. 137-167, 2011.

GRAY, J. Pluralismo de valores y tolerancia liberal. Estudios públicos, v. 80, p. 77-93, 2000.

HARVEY, David. O Neoliberalismo: História e Implicações. 4a Edição, São Paulo: Edição Loyola, 2013.

IANNI, Octávio. A era do globalismo. 3. ed. Rio de Janeiro, RJ: Civilização Brasileira, 1997.

IANNI, O. A política mudou de lugar. São Paulo em perspectiva, v. 11, n. 3, p. 3-7, 1997.

IBARRA, D. O neoliberalismo na América Latina. Revista de Economia Política, v. 31, p. 238-248, 2011.

LOURENÇO, C. A. P.; AFONSO, M. L. M. Educação em direitos humanos no ensino superior: estratégias políticas, teóricas e metodológicas. Revista Competência, v. 8, n. 1, 2015.

LÖWY, M. Conservadorismo e extrema-direita na Europa e no Brasil. Serv. Soc. Soc., São Paulo, n. 124, p. 652-664, Dez. 2015. Disponível em: <http://www.scielo.br/scielo.php?script=sci_arttext\&pid=S0101$66282015000400652 \&$ Ing=en\&nrm=iso>. Acesso em 09 jun. 2017.

MAGENDZO, Abraham. Educación en derechos humanos - un desafío para los docentes de hoy. Santiago: LOM Ediciones, 2006.

OLIVEIRA, D. B. R.; MACHADO, E. R. Movimentos ultraliberais no brasil - "Movimento Brasil Livre" e "Vem pra Rua". XI Seminário de Pesquisa em Ciências Humanas - SEPECH, Londrina, 2016.

PAXTON, Robert Owen. A anatomia do fascismo. São Paulo, SP: Paz e Terra, 2007.

PIOVESAN, F. A constituição brasileira de 1988 e os tratados internacionais de proteção dos direitos humanos. Revista Jurídica da Faculdade de Direito/Faculdade Dom Bosco. Núcleo de Pesquisa do Curso de Direito. V. 2, n. 1, p. 20-33, jan./jun. 2008.

RAWLS, John. Uma teoria da justiça. São Paulo: Martins Fontes, 2002.

SALVIOLI, Fabián. La universidad y la educación en el siglo XXI: los derechos humanos como pilares de la nueva Reforma Universitaria. Instituto Interamericano de Derechos Humanos. San José: IIDH, 2009.

SANTOS, Boaventura de Sousa. Reinventar a democracia: entre o pré-contratualismo e o pós-contratualismo. 1998. 
A EDUCAÇÃO EM DIREITOS HUMANOS DIANTE

DA ASCENSÃO DO "NOVO FASCISMO"

TONET, I. Cidadania ou emancipação humana. Revista Espaço Acadêmico, n. 44, 2005.

TONET, I. Para além dos direitos humanos. Revista Novos Rumos, n. 37, 2012.

TOSI, G. Direitos humanos como eixo articulador do ensino, da pesquisa e da extensão. 2005.

VIEIRA, R. M. A construção do consenso ultraliberal. RAE Eletrônica, v. 5, n. 2, 2006.v 